\title{
Language Confidence and Acquisition: Perception of Accent Affects Oral Speaking Skill in Second Language Acquisition
}

\author{
Yongqi Dong ${ }^{1}$, Tianao Gui², Meien Zhang ${ }^{3}$, Yan Zhong ${ }^{4, *}$ \\ ${ }^{1}$ Faculty of Humanities, The Education University of Hong Kong, Hong Kong, China \\ ${ }^{2}$ Shanghai Foreign Language School affiliated to SISU, Shanghai, 200083, China \\ ${ }^{3}$ Canadian International School of Beijing, Beijing, 100012, China \\ ${ }^{4}$ The Cambridge School of Dallas, Dallas, 75231, USA \\ *Correspondence Email: jyyyeon@gmail.com
}

\begin{abstract}
As more people are learning a second language nowadays, it seems that having an accent would influence people's second language acquisition. Different from the standard native way of speaking, an accent is oftentimes considered negatively by people due to the implication of the lack of knowledge and the difficulty in communication. People are self-conscious of their accents and the judgment coming from others when speaking a new language, and this may lead to a decline of interest. Therefore, the purpose of this study is to draw people's attention to the lack of study in the relationship between self-assessment and second language acquisition. This paper will investigate the correlation between Chinese teenagers' awareness of their accents and their oral English skills. In order to have a both subjective and objective language skill evaluation, participants are given a self-report survey and evaluated by the speaking part of the IELTS test in the experiment. Every alternative answer is carefully discussed in the design, and the correlation of the two results is going to be investigated by regression analysis. This paper can help learners acquire their second language more efficiently by pointing out the importance of language confidence, which reveals a new perspective that having an accent should not be shameful.
\end{abstract}

Keywords: Second language acquisition (SLA), Language confidence, Accent perception, Oral language skills, Linguistic psychology.

\section{INTRODUCTION}

More and more people are starting to learn a second language (L2) nowadays, but having a foreign accent is an inevitable phenomenon that everyone would encounter. There is a rise of language anxiety which produces people's feeling of unease, apprehension, and nervousness. The lack of confidence not only impedes people's language learning achievement but also the learning experience and self-confidence. Language anxiety can lead to other potential problems like a decline in self-esteem. Gasquet-Cyrus showed that people were aware of others' biases when they spoke with a different accent [1]. This means that considering accent as a negative thing might have influences on speakers. According to the Critical Period hypothesis (CPH), there is a "critical period for speech" during which learners can acquire a second language without an accent [2]. Therefore, it is common for foreign language learners to have an accent different from native speakers when they learn an L2 after that period. This leads to the question of whether having an accent would influence on people's second language acquisition (SLA). Kameron indicated that the majority of the research participants felt that the non-native accents put them at a disadvantage due to people's judgment about their lack of knowledge and results in communication difficulties [2]. This might reduce people's confidence in speaking a new language when they are aware of this disadvantage, which affects and results in a decline in their second language acquisition. To prove this hypothesis, the primary objective of this paper is to determine whether people's awareness of their foreign accents affects their oral speaking skills in second language acquisition. 


\section{BACKGROUND}

A large number of research had already mentioned both accent and second language acquisition in their studies. These studies consist of three main categories. The first focuses on speaker-dependent factors such as the age of learning. For example, the study conducted by Moyer indicated that age of language exposure was one factor that affects language learning: when people are exposed to a second language earlier, they are more likely to speak without an accent [3]. Besides this, Moyer discovered that cognitive, psychological, and social factors also contributed to the outcome of foreign language learning by using quantitative and qualitative analyses [3].

The second kind of studies emphasized investigating the phonological structure which caused foreign accents. For instance, Major explained the reason for foreign accents by analyzing second language phonological systems and language change by Ontogeny Phylogy Model [4]. The Ontogeny Phylogy Model is a model used for claiming the basic pattern of interlanguage's development: the second language increase, the first language decrease, and universals increases and then decreases [4].

And the last aspect of studies delves into the impact brought by accent in second language acquisition. Researchers start to consider whether having accents would have effects on interlocutors. Munro stated that a foreign accent was related to comprehensibility and intelligibility, but a strong foreign accent would not result in low comprehensibility and intelligibility [5]. However, Zuengler said that though accent played a little impact on intelligibility, the accent was associated with stronger social bonds [6].
From the studies listed above, it is clear that the existing research concerning accent and second language acquisition focus on factors that cause accents such as age exposure and phonological factors. Though there are research elaborating on how accent influences second language learning, their focus is more about listeners instead of learners. Existing research pay more attention to listeners' comprehensibility about accent instead of the effect brought by accent to learners themselves. Hence, this study would exert the emphasis on learners instead of listeners by studying the effect of accents on learners' speaking skills.

\section{PROPOSED STUDY}

Since the studies conducted on the impact of selfassessment and how that affects language acquisition are very limited. This proposed study will investigate whether learners' awareness of their accent affects their English oral speaking skills. We hypothesize that if the participants don't think that they have a foreign accent while speaking, even if they in fact do, their language learning is not affected by it, so they have a better English oral speaking performance than those who think that they do have an accent. If they think that they do have a foreign accent, no matter true or not, they generally have worse speaking skills. Because their self-assessment, thinking negatively of their accents, does affect their language learning; The alternative hypothesis is that the participants would have better oral English skills if they conclude that they do have an accent, and that if they don't think that they have an accent then they would have worse oral English skills. The third alternative answer is that there is no correlation between their self-assessment of their accent and their oral English speaking skills.

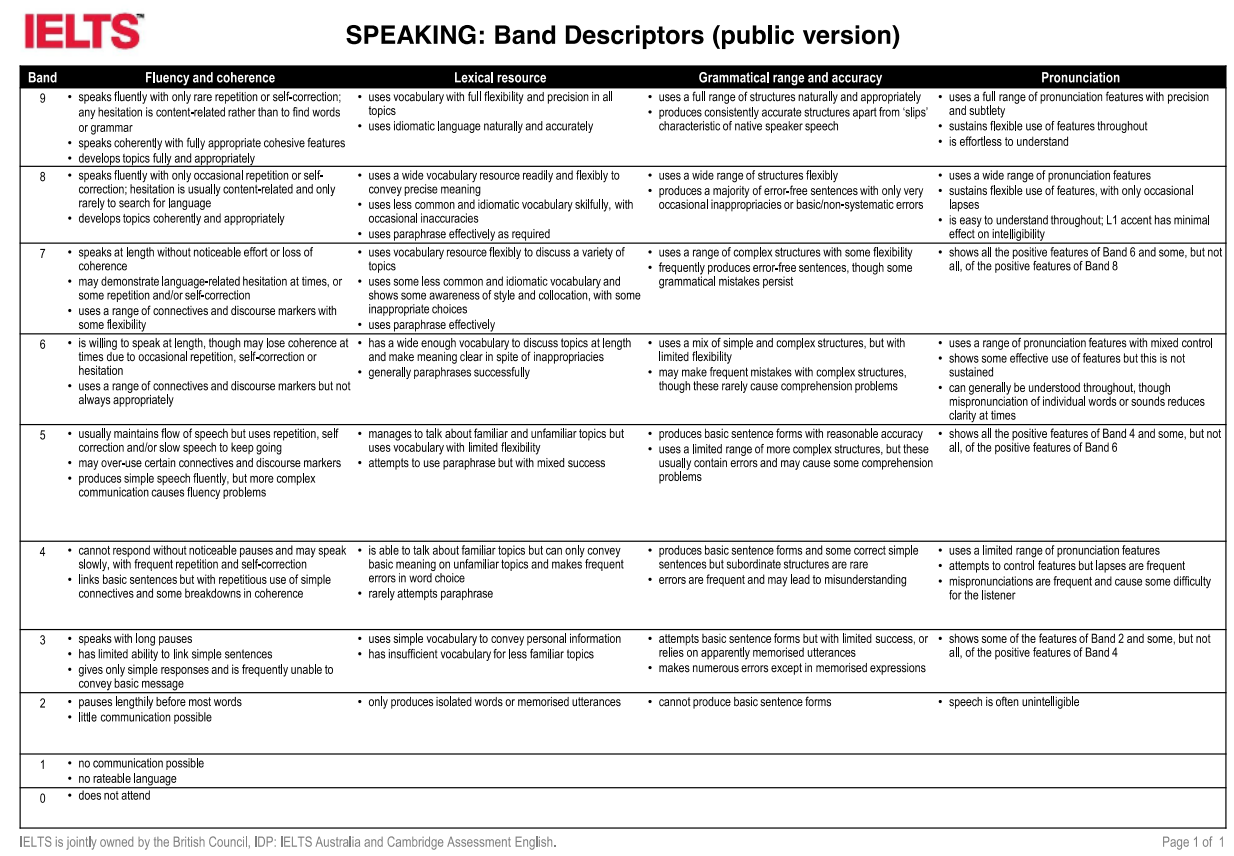

Figure 1: IELTS Speaking Part Scoring Rubric 
We are going to give the participants a self-report survey that consists of questions that require them to reflect on their oral English speaking skills based on their own judgment. And in order to evaluate their real speaking skill levels objectively, we will have them participate in the speaking part of the IELTS test, the International English Language Testing system, to get a relatively authoritative evaluation (accents, as a confounding variable, are not taken into consideration in the IELTS test grading). The scoring criteria of the test are based on intelligibility such as grammatical accuracy and coherence, so it reflects an objective oral skill in which the accent is not included. Additionally, in order to increase the reliability of the experiment, there is going to be only one IELTS professional examiner, and the questions are going to be the same for each participant.

\section{METHOD}

\subsection{Participants}

This study will be based on an experiment and a survey. It will involve $\mathrm{N}=50$ native Chinese speakers aged 18 years old who learn English as a foreign language with similar scores in English listening, reading, and writing exams. The participants will be selected from normal Shanghai high schools where the Chinese national curriculum is taught. We believe $\mathrm{N}=50$ will be enough to yield a representative result. We choose teenagers because they may be more familiar with English than people of other ages.

\subsection{Materials}

A silent room will be needed for participants to do the speaking part of the IELTS test. An expert examiner will participate in the test and score the performance of each participant. After that, a survey about accents will be sent out to the participants. Each participant will give a score from 1 to 7 . ( $1=$ strongly disagree to $7=$ strongly agree $)$. The designed survey will include questions below:

1. I have a strong non-native English accent.

2. I have problems using oral English because of my accent.

3. My accent impedes others' comprehension of my oral English.

\subsection{Procedures}

First, all the participants will be asked to finish the speaking part of the IELTS test with a professional examiner in a silent lab room. Then, all participants will respond to the designed survey based on their real personal situations. After that, the examiner will give a score to every teenager.

\subsection{Results and Discussion}

In order to get the result, we will use regression analysis to investigate the correlation between the two variables: the scores of the survey and the scores of the IELTS tests of each participant. If the correlation coefficient is between -1 and -0.7 , then a strong negative correlation exists between the two variables. We can conclude that self-awareness of a foreign accent impedes the oral skills of a foreign language. If the correlation coefficient is between 0.7 and 1 , then being aware of a foreign accent actually promotes the oral skill of a foreign language. And if the correlation coefficient is between 0.7 and 0.7 , then the correlation is too weak or does not exist. This will indicate that there is no notable connection between the awareness of a foreign accent and oral skills of a foreign language.

\section{Compare the 2 sets of data: IELTS scores \& survey scores}

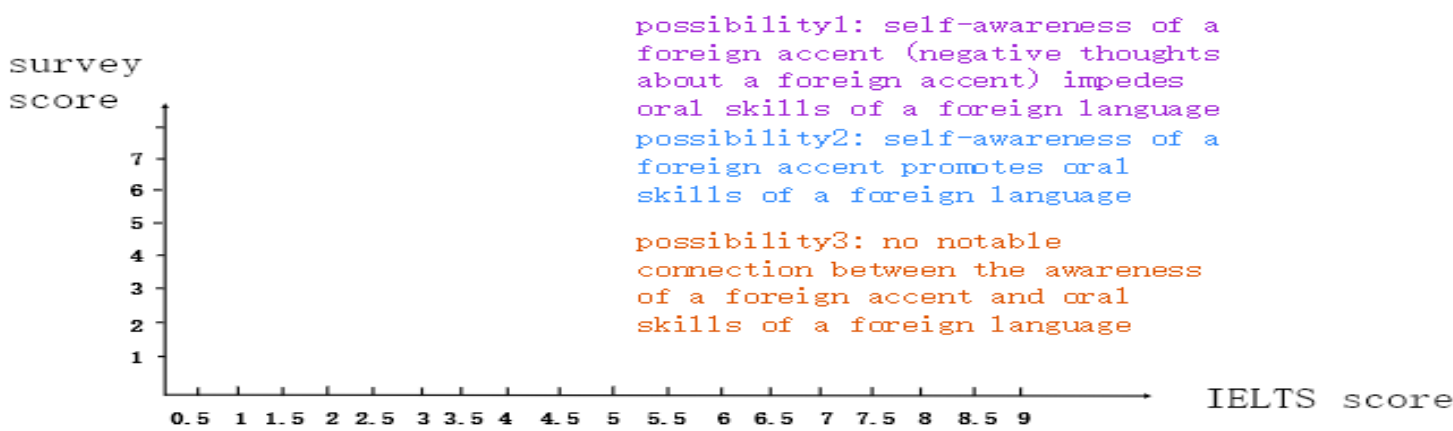

Figure 2: Comparison of the IELTS Result and the Survey Result 


\section{CONCLUSION}

\subsection{Limitations of the Present Study}

A prominent limitation of the present study is that it is specific to the Chinese learners' acquisition of oral English skills at the age of 18 . Due to social and educational variations, groups of different backgrounds may emphasize different components of a language. For instance, learners of a country that pay more attention to accent may assess their accent differently compare to learners of another country that focus more on grammar. Furthermore, users of different languages can have different levels of difficulty in acquiring another language, and this may be determined by the degree of similarity between the two languages. This is demonstrated by Chinese speakers' acquisition of Japanese may be easier than that of English as the languages possess more commonality. Hence, the present study may not be generalizable to speakers of other groups. Furthermore, the method of using the IELTS exam's speaking component can cause inaccuracies in terms of the comprehensiveness in examining the subjects' speaking skills, as it is a standardized test that consists of a particular examination style and has a fixed marking standard. Subjects' familiarity with the exam questions' style and their ability to answer certain questions may impact their test score, while this variable is independent of their English oral skills. This problem is especially noteworthy considering some of the subjects may have taken similar language exams before, thus are more familiar and more experienced with the questions.

\subsection{Directions for Future Research}

Indicated by the limitations of the present study, there are areas that remain for further exploration regarding this topic. Future studies could look into a wider range of language acquisition regarding other aspects of language including: reading, writing, and listening. As language acquisition is comprehensive, factors that influence the oral aspect would also have an effect on other aspects. In addition, the exploration could be applied to a wider range of groups with more variety in characteristics such as age and culture. Specifically, more language combinations can be studied other than Chinese-English. Moreover, the impact of other factors on oral language acquisition can be looked into more as accent is only one of the influential factors.

\section{REFERENCES}

[1] Gasquet-Cyrus, M. (2012). La discrimination à l'accent en France: idéologies, discours et pratiques. Trimaille C., Eloy J.-M.(éd.) Idéologies linguistiques et discriminations. Paris: L'Harmattan, Carnets d'Atelier de Sociolinguistique, UPJVLESCLaP(CERCLL) EA4283, 6, 227-245.
[2] Kameron, S. E. (2014). Pronunciation ego: Accent and confidence in a second language.

[3] Moyer, A. (2004). Age, accent, and experience in second language acquisition. Multilingual Matters. https://doi.org/10.21832/9781853597190

[4] Major, R. C. (2001). Foreign accent: The ontogeny and phylogeny of second language phonology. Routledge.

[5] Munro, M. J., \& Derwing, T. M. (1995). Foreign accent, comprehensibility, and intelligibility in the speech of second language learners. Language learning, 45(1), 73-97. https://doi.org/10.1111/j.1467-1770.1995.tb00963.x

[6] Zuengler, J. (1988). Identity Markers and L2 Pronunciation1. Studies in Second Language Acquisition, 10(1), 33-49. 